\title{
Stock Model Based Bottom-up Accounting for Washing Machines: Worldwide Energy, Water and Greenhouse Gas Saving Potentials 2010-2030
}

Washing laundry is one of the most widespread housework tasks in the world. Washing machines, performing this task already in many private households, are now responsible for about $2 \%$ of the global electricity consumption. Worldwide, more than 840 million domestic washing machines are in use, with an annual consumption exceeding 92 TWh of electricity and 19 billion $\mathrm{m}^{3}$ of water as well as causing emissions of more than 62 megatons $\mathrm{CO}_{2}$ eq. In North America, Western Europe and Pacific OECD countries, most households own a washing machine. In these economies standard and label policy programs already addressed and reduced the specific electricity and water consumption of washing machines per wash cycle. Nevertheless, in other world regions, the level of ownership for washing machines is still well below saturation and high growth rates can be observed in developing and newly industrialising countries. As washing machines use water, electricity, chemical substances and process time as resources, also the absolute worldwide resource consumption and emissions of these appliances are still on the rise. Due to different washing habits and practices as well as types of washing machines in different world regions, the specific consumption of resources for doing the laundry is varying to a large extent. On that score, this paper presents an overview of the current situation worldwide as well as respective saving potentials. Bottom-up scenario calculations, carried out for the 11 world regions according to the Intergovernmental Panel on Climate Change classification, show that large energy, water and greenhouse gas savings are possible with the 'Best Available Technologies' today, and even higher savings will be possible with next generation 'Best Not yet Available Technologies'. According to model results, these savings are usually also very cost-effective. Following these calculations, it is highly advisable for policymakers world-wide to pay even more attention to improvement options in order to implement ambitious and product-specific policy packages, including minimum performance standards and labelling schemes.

Key words: Washing machines, bottom-up modelling, energy efficiency, water consumption, saving potentials

Bottom-up-Berechnungsmodell für Waschmaschinen: Weltweite Einsparpotenziale an Energie, Wasser und Treibhausgasen von 2010 bis $\mathbf{2 0 3 0}$. Waschen von Wäsche ist weltweit eine der häufigsten vorkommenden Arbeiten im Haushalt. Waschmaschinen, die diese Arbeit bereits in vielen Haushalten durchführen, haben einen Anteil am globalen Stromverbrauch von etwa $2 \%$. Weltweit sind mehr als 840 Millionen Haushaltswaschmaschinen mit einem Jahresverbrauch von mehr als
92 TWh Strom und 19 Mrd. $\mathrm{m}^{3}$ Wasser im Einsatz. Sie verursachen Emissionen von mehr als 62 Megatonnen $\mathrm{CO}_{2}$ - ̈̈quivalent. In Nordamerika, Westeuropa und den Pazifik-OECD-Ländern besitzen die meisten Haushalte eine Waschmaschine. In diesen Volkswirtschaften haben sich politische Standardisierungs- und Kennzeichnungsprogramme damit befasst, den Verbrauch an Elektrizität und Wasser der Waschmaschinen pro Waschzyklus zu reduzieren. In anderen Regionen der Welt ist der Besitz an Waschmaschinen immer noch deutlich unterhalb der Sättigung und hohe Wachstumsraten können in Entwicklungs- und Schwellenländern beobachtet werden. Da Waschmaschinen Ressourcen an Wasser, Strom, chemischen Substanzen und Prozesszeit verbrauchen, steigen der absolute weltweite Ressourcenverbrauch und die Emissionen dieser Geräte sind immer noch an. Aufgrund der unterschiedlichen Waschgewohnheiten und Praktiken sowie der vielen Waschmaschinentypen in verschiedenen Regionen der Welt, variiert der spezifische Verbrauch von Ressourcen für das Wäschewaschen sehr stark. In diesem Punkt stellt dieser Beitrag einen Überblick über die aktuelle weltweite Situation sowie die entsprechenden Einsparpotenziale dar. Bottom-up-Berechnungen von Szenarien, die für 11 Weltregionen gemäß der Klassifikation des Zwischenstaatlichen Ausschuss über Klimaveränderung durchgeführt wurden, zeigen, dass große Einsparungen an Energie, Wasser und Treibhausgas nach dem heutigen Stand der Technik möglich sind und sogar noch größere Einsparungen mit der nächsten, noch nicht verfügbaren TechnikGeneration erreicht werden können. Entsprechend der Resultate der Modellrechnungen sind die Einsparungen in der Regel auch sehr kosteneffektiv. Diesen Berechnungen zufolge ist es für die politischen Entscheidungsträger weltweit ratsam, mehr Aufmerksamkeit den Verbesserungsmöglichkeiten zur Umsetzung ehrgeiziger und produktspezifischer Maßnahmenpakete einschließlich der Mindestleistungsstandards und Kennzeichnungssysteme zu widmen.

Stichwörter: Waschmaschinen, Bottom-up-Modelle, Energieeffizienz, Wasserverbrauch, Einsparpotenziale

\section{Introduction}

Washing machines (WM) are one of the most widely used residential appliances all around the world [1], causing significant environmental impacts, especially by their electricity consumption [2]. In addition, the water consumption of washing machines is another highly relevant resource aspect [3], in particular in world regions with severe water shortages [4]. This raises the question on the dimension of 
the electricity and water consumption by washing machines in the different world regions and worldwide [1]. Thereby, the development of the absolute numbers of installed appliances and their specific unit energy and water consumption has to be analysed to assess total consumption levels and how they will develop in the future [5].

It is well known from international appliances databases presenting the most efficient products worldwide (e.g. www.topten.info or www.energystar.gov), that significant differences in resource consumption between the average and the most efficient appliances exist [6]. Based on this, it can be assessed, what is the available technical saving potential, e. g. if only the most efficient appliances are purchased. This is especially relevant to support the development of effective policies required for a faster market transformation towards much more efficient appliances [5].

\section{Overview of washing technologies and technical background}

In general, domestic washing machines can be assigned to two different main categories, depending on the orientation of the drum rotation axis [7]:

\subsection{Horizontal axis (HA) machines}

In horizontal axis machines, only the bottom of the drum needs to be filled with water, and thus, significantly less water per wash cycle is used compared to similar sized vertical axis machines. HA machines are typically equipped with an internal electric water heating system. Hence, the energy consumption heavily depends on the chosen washing temperature and the actual amount of water to be heated [1]. Modern HA washing machines have an automatic load sensing function in order to reduce water and electricity consumption in response to consumer loads that are smaller than the rated washing capacity. Horizontal axis machines are gaining market shares in almost all markets worldwide [7].

\subsection{Vertical axis (VA) machines}

Traditionally, the tub of vertical axis machines is entirely filled with water. Most modern machines also have automatic water level settings or the user can set the water level manually, but even state of the art VA machines often consume about twice as much water per wash cycle as similar sized HA machines [4]. Although VA machines are usually not equipped with an integrated electric water heating system, warm washes can be done manually or via separate inlets by using preheated water from external domestic hot water sources. This external energy is hard to estimate, because it is a user induced procedure and can be done by electricity or other energy sources like gas, coal, oil or solar power [1]. Vertical axis machines are still most widespread in America, Australia and Asia [7].

\subsection{Sub types of washing machines}

Within the two basic categories, washing machines vary in their specific configurations and the range of additional options [7]. The most common sub types of automatic washing machines worldwide are presented in the following sections:

\subsubsection{Horizontal axis, front- or top loading washing machines}

These machines are popular especially in Europe, but the shares of front-loading HA machines are steadily increasing in other markets worldwide. Given the same washing temperature and load, switching from VA to efficient HA machines offers high water and energy saving potentials, as HA machines usually consume significantly less (pre-) heated water per wash cycle than VA machines [7].

In a HA washing machine, the textiles are placed in a horizontal drum and need only to be partially immersed in the washing water. The required mechanical action as well as the contact to water and detergents is thereby provided by the rotation of the drum about its axis. The drum is accessible either from one single door on the front (most popular front-loader configuration) or from several adjacent doors on the top of the machine and the drum (top-loader configuration as 'niche' product). Many traditional HA machines have a minimum program temperature of $30^{\circ} \mathrm{C}$, which means that electricity is used to heat up water even in the coldest program selectable [1]. Since the introduction of high efficient low-temperature detergents, most new models have been equipped also with $20^{\circ} \mathrm{C}, 15^{\circ} \mathrm{C}$ and "cold wash" programs to reduce energy consumption on user demand.

\subsubsection{Vertical axis, top loading, agitator type washing machines}

In this type of top loader washing machines the mechanical action is provided by a pole-shaped agitator, which is usually extending above the maximum water level in the tub. This device moves about or along its vertical axis with a reciprocating motion. If cold water is used, energy consumption per wash cycle is comparatively low. But although VA machines are typically not equipped with internal heating systems, the reported washing temperature is often higher than expected. E.g. in North America, the average is about $30^{\circ} \mathrm{C}$, equalling to an electricity consumption of about $0.43 \mathrm{kWh}$ per wash cycle [1]. This might include warm water from the tap and thus energy from various external resources, which are hard to quantify. VA agitator type machines are especially popular in North- and Latin America [7].

\subsubsection{Vertical axis, top loading, impeller type washing machines}

Impeller type washing machines are popular especially in Asia (e.g. China, South Korea, Japan) and Australia [7]. In this type of washing machines the mechanical swirl-action is produced by a flat central element rotating about its axis, which is named by most manufacturers as 'impeller'. During operation, the uppermost point of this impeller device is substantially below the minimum water level in the drum [7]. This type of washing machines is traditionally designed as top-loading device with the tub accessible from one single door on the top. If cold water is used, the overall energy consumption per wash cycle is low. However, although vertical axis impeller machines are usually not equipped with an internal water heating system, the usage of preheated water from external sources through dedicated hot water inlets is commonly possible [1].

Occasionally, impeller-type washing machines are also referred to as "high efficiency top loader washers" (especially in North America [8]) due to a different washing process and a reduced water usage compared to inefficient agitator-type models [7]. Nevertheless, an often reported higher usage of bleach and other detergents, as well as washing treatments with relevant amounts of water and energy outside the washing machine may indicate only a mediocre level of washing performance provided by these machines [1]. 


\section{Bottom-up stock model accounting methodology}

The bottom-up accounting stock model used for the purposes of this paper is a further adapted version of the DEESY Stock Model [9] developed by the Wuppertal Institute, which assesses scenarios with special focus on energy and water consumption as well as greenhouse gas emissions. According to the expected development of the stock volume and the typical lifetime of an appliance [10] (15 years for washing machines [6]), the model calculates the per-annum market volume for each year within the covered scenario time period (2010 to 2030), including the first-time acquisition as well as the replacement of end-of-life appliances. The techno-economical characteristics of the typical product purchased in a certain year are dependent on the Base Case and Best Available Technology (BAT) available at the time of purchase and on a weighting factor reflecting the level of energy efficiency presumed for the respective scenario.

Next generation BNAT "Best Not yet Available Technologies" becoming more efficient in terms of electricity and water consumption each year are also considered in the model, as well as incremental costs for these product improvements. The modelling of the historical appliance stock purchased within the 15 years in advance of the covered scenario time period (1995 to 2009) is essentially based on the same methodology. However, the development of these preceding years is additionally calibrated for the base year (2010) to meet the expected stock volume numbers in this reference year.

In order to assess the overall technical saving potentials of the most efficient appliances, two major scenarios are subsequently presented and compared: a baseline scenario with moderate efficiency improvements according to current trends and base case products having 100\% market share after the selected starting year 2010, as well as a maximum energy efficiency scenario, assuming a $100 \%$ market share of BAT products. The characteristics of the base case and BAT products are derived from a comprehensive country specific bottom-up technology analysis, which was performed as preparatory work for the modelling. Thereby, different economic and market specific regional conditions have been taken into account for the model input parameters.

\section{Results from bottom-up stock modelling for washing machines worldwide}

In the following, the combined worldwide results of the performed bottom-up scenario analysis for washing machines are presented. Thereby, for the defined main reference years 2010, 2020 and 2030 all 11 world regions according to the Intergovernmental Panel on Climate Change (IPCC) systematic are considered: Sub-Saharan Africa (AFR), Centrally planned Asia and China (CPA), Latin America and the Caribbean (LAM), Middle East and North Africa (MEA), North America (NAM), Newly Independent States (NIS), Pacific OECD (PAO), Other Pacific Asia (PAS), South Asia (SAS) as well as (summarized) Western, Central and Eastern Europe (WEU and EEU).

Based on data from [1], other relevant reports by [3] and [5] as well as comprehensive own research, about 840 million domestic washing machines were in use worldwide in the model starting year 2010. The calculated average annual consumption of each of these washing machines amounted to about $110 \mathrm{kWh}$ of electricity and $23 \mathrm{~m}^{3}$ of water. With an overall electricity consumption of about 92 TWh per year, they accounted for about $2 \%$ of the total electricity con- sumption of the residential sector worldwide [11]. Furthermore, the 2010 world wide stock of washing machines also consumed about 19 billion $\mathrm{m}^{3}$ of water and caused worldwide greenhouse gas emissions of 62 million tons of $\mathrm{CO}_{2}$ eq.

Starting from 2010, in the efficiency scenario a relative decoupling of the growth of the worldwide annual energy and water consumption and the increasing stock of domestic washing machines can be achieved. While the stock is expected to grow by $36 \%$ between 2010 and 2020, in the efficiency scenario the energy consumption would only increase by $12 \%$ (see Fig. 1) and the water consumption by $5 \%$ (See Fig. 2). Although the world-wide stock of washing machines is expected to grow by another $26 \%$ between 2020 and 2030, in the efficiency scenario the increase of the energy and water consumption would be limited to about half of that value. In contrast, the baseline scenario energy and water consumption levels increase significantly by $43 \%$ and $15 \%$ by 2020 and additionally by $35 \%$ and $18 \%$ from 2020 to 2030 .

If worldwide every time a washing machine is purchased the most energy- and water-efficient model is chosen instead of a standard model (as assumed in the efficiency scenario), 31.5 TWh of electricity, 2.2 billion $\mathrm{m}^{3}$ of water and 20.8 million tons of $\mathrm{CO}_{2}$ eq can be saved in the reference year 2020 compared to the baseline development. Moreover, even 65 TWh of electricity, 3.6 billion $\mathrm{m}^{3}$ of water and 42.4 million tons of $\mathrm{CO}_{2}$ eq can be saved in the reference year 2030 compared to the baseline. Thereby it has to be considered that the worldwide stock of washing machines in this period is expected to rise significantly from 840 million units in 2010 over 1.14 billion units in 2020 to 1.44 billion units in 2030 .

By means of the broad diffusion of efficient new technologies, the average annual energy and water consumption of all new washing machines worldwide can be reduced from $110 \mathrm{kWh}$ and $23 \mathrm{~m}^{3}$ in 2010 , over $80.1 \mathrm{kWh}$ and $16.2 \mathrm{~m}^{3}$ in 2020 to $75.7 \mathrm{kWh}$ and $14.8 \mathrm{~m}^{3}$ in 2030 . Overall, the stock model results for lifetime savings for all domestic washing machines purchased worldwide between 2010 and 2030 show that a cumulated amount of 1,218 TWh of energy, 72 billion $\mathrm{m}^{3}$ of water as well as 785 megatons of $\mathrm{CO}_{2} \mathrm{eq}$ can be saved in the efficiency scenario compared to the baseline development.

\section{Discussion of bottom-up scenario calculations}

\subsection{General aspects}

The performed bottom-up calculations demonstrate that large efficiency improvements can be achieved globally if systematically the most efficient washing machines available on the market are purchased (efficiency scenario) instead of standard technologies (baseline scenario). Thereby, higher living standards, represented by increasing appliance ownership rates, a more frequent usage of warm wash cycles as well as a technological change towards more water efficient horizontal axis washing machines have been generally anticipated.

For the further interpretation of the bottom-up model results, it has in particular to be considered that the distribution of domestic washing machines is very uneven between different world regions. This uneven distribution of domestic washing machines worldwide, different types of machines and their various efficiency levels, as well as different wash habits and practices (e.g. wash temperatures, number of wash cycles per year) lead to substantial disparities in electricity and water consumption within the different world 


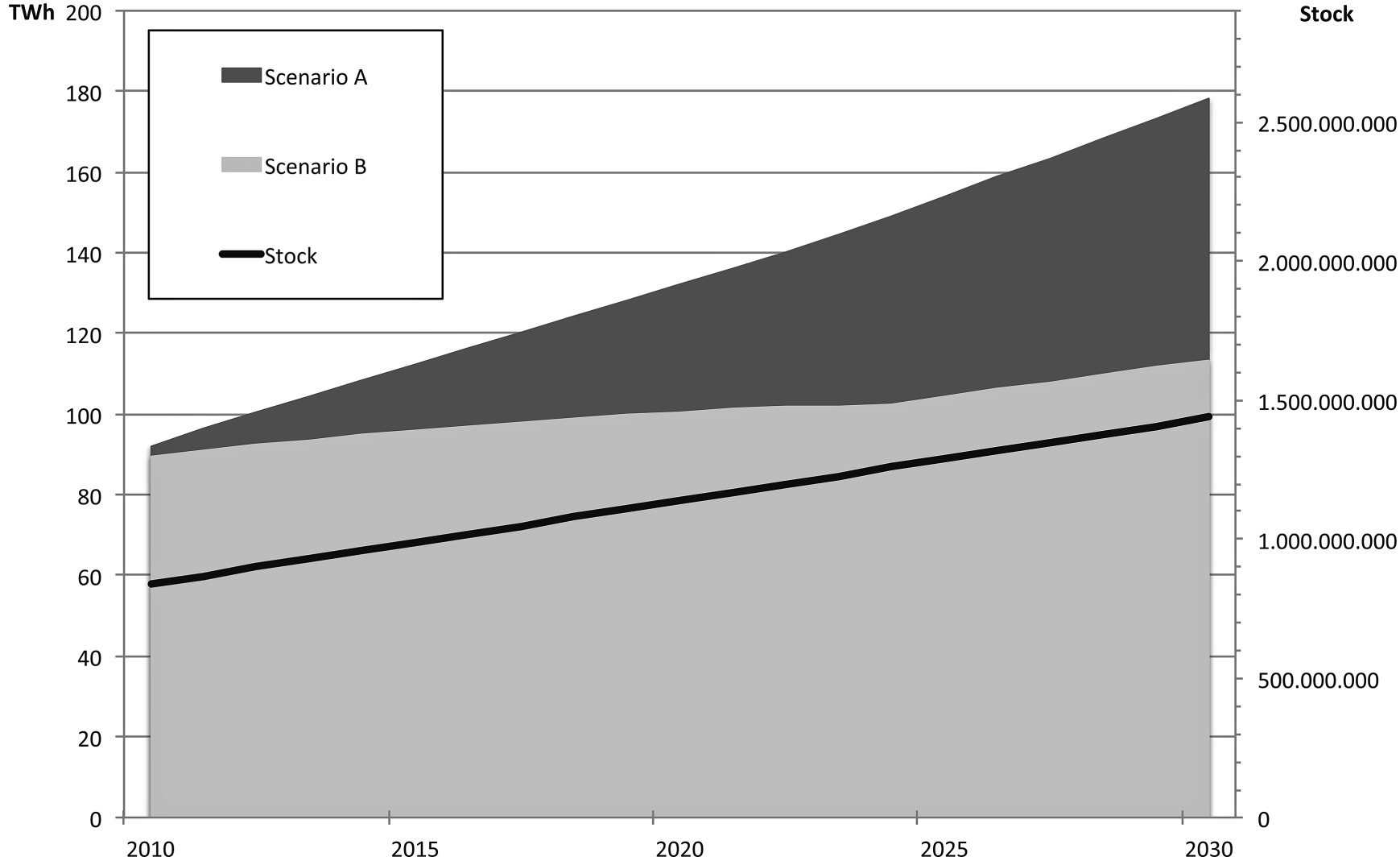

Figure 1 Stock development and total electricity consumption of domestic washing machines, Baseline Scenario A compared to Efficiency Scenario B (own calculation and graphic)

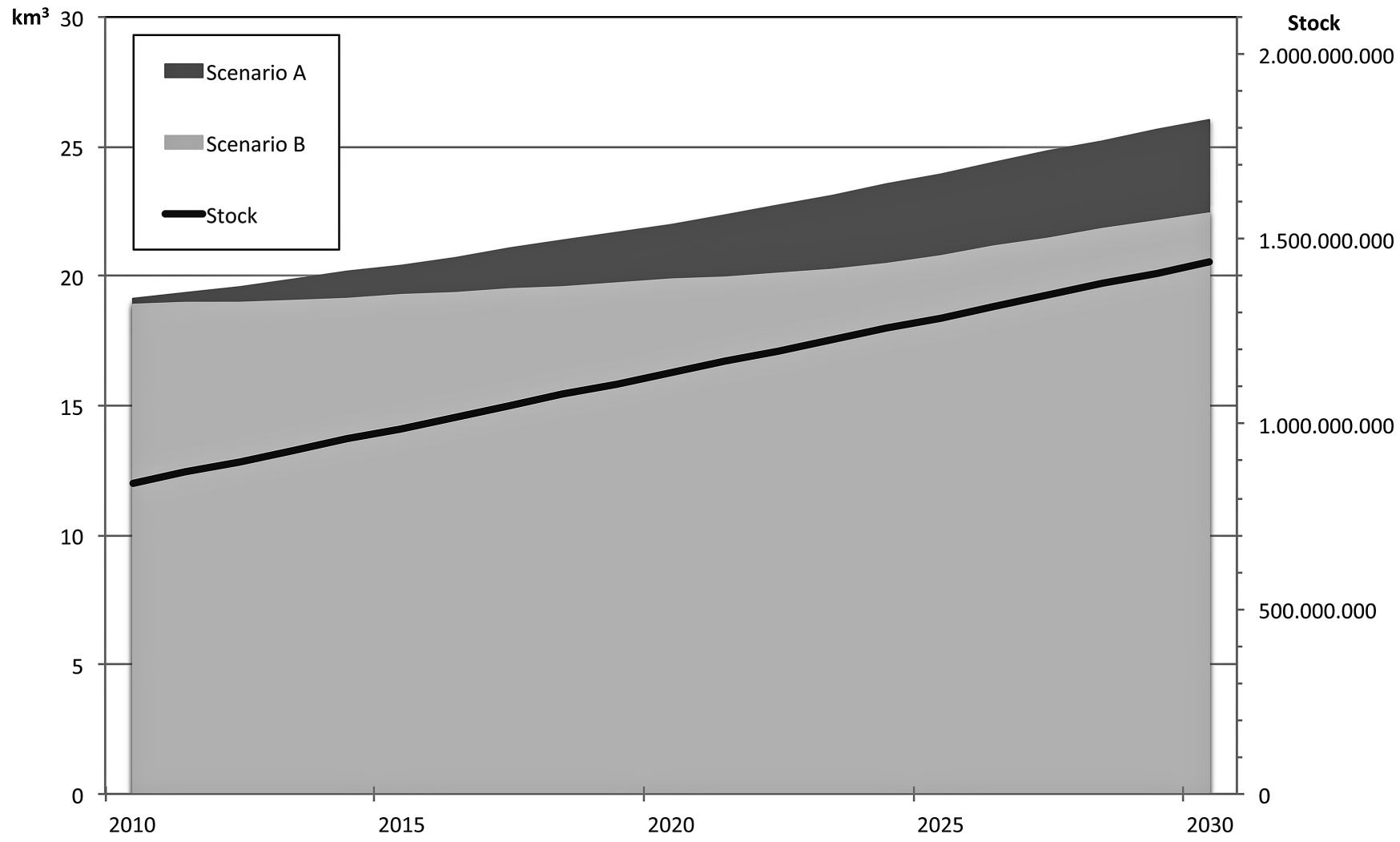

Figure 2 Stock development and total water consumption of domestic washing machines, Baseline Scenario A compared to Efficiency Scenario B (own calculation and graphic) 
regions. Accordingly, also the available saving potentials are varying significantly.

In this context, specificities of the most relevant lead markets for each major type of washing machines are presented and discussed exemplarily in the following sections. Thereby already saturated markets in industrialized regions as well as example regions with very strong growth rates and large market potentials have been selected. As these indicator countries and regions have strong influence e.g. regionally or as global export nations, the respective findings can be also transferred to most other countries or world regions, which are characterized by similar wash habits and technologies or a respective mixture thereof.

\subsection{Discussion in the context of worldwide leading markets}

\subsubsection{North America (NAM)}

In North America, vertical axis (mostly agitator type) washing machines are still widespread and represented more than $80 \%$ of the stock in the starting year of the scenarios [12]. The stock of washing machines in NAM is still increasing, from about 107 million installed units in 2010 to expected 149 millions units in 2030, also as consequence of the growing number of smaller households.

Although average washing temperatures $\left(15-48^{\circ} \mathrm{C}\right.$ [1]) are lower than in countries with traditionally mainly HA technology and the common usage of hot-wash programmes (e.g. Europe), the usage of washing machines in North America also causes a significant consumption of resources. Due to the water intensive VA technology, more water has to be heated in case of warm or hot wash programs. Thereby, commonly pre-heated water from the tap is used, which is heated by external water heaters [7]. Furthermore, as cleaning performance depends on mechanical work, thermal energy, chemicals and time, as in other regions with prevailing VA washing machines, a better cleaning performance is of ten achieved by an extra input of detergents or mechanical energy outside the washing machine. In addition, North American households run on average also more wash cycles per year than e.g. households in Europe [1].

Consequently, the best opportunity to reduce energy and water consumption despite the still increasing stock in NAM is to shift from VA to more effective and efficient HA technology, while keeping the washing temperatures at the same or lower levels. Furthermore, running the machines mostly filled up to nominal load could reduce the number of wash cycles. By using the available efficiency potentials, stock model results for NAM indicate that electricity savings of $22.8 \%$ can achieved in 2030 , when comparing the absolute energy consumption of WM in the efficiency scenario (14.6 TWh/year) with the baseline scenario (18.9 TWh/year).

\subsubsection{Western, Central and Eastern Europe (WEU/EEU)}

The absolute numbers of installed washing machines in Western, Central and Eastern Europe are still expected to rise from about 193 million (2010) to 240 million units in 2030, also as consequence of the growing number of smaller households.

The average electricity and water efficiency of Western European horizontal axis washing machine technology has been improved by more than one third in the last decades, which is mainly a result of the energy efficiency policy by the European Union [3]. Due to the efficient water consumption of efficient new HA washing machines, households in Europe use less water per wash cycle and year than most other regions in the world [1]. This development is not only a result of continuous technology optimisation, but in particular a success of banning the least efficient models by EU Ecodesign measures and to foster efficient products by energy labelling. However, e. g. in contrast to NAM, horizontal axis washing machines with integrated electric heating rods are common in Europe and consequently the usage of warm and hot wash cycles is much more widespread.

Therefore major savings are still possible by replacing old units and avoiding too hot wash programmes. Using the full nominal load of new machines can reduce the annual number of wash cycles. Overall, stock model results for Europe reveal electricity saving potentials of $27.1 \%$ in 2030, when comparing the absolute energy consumption of WM in the efficiency scenario (21.2 TWh/year) with the baseline scenario (29.1 TWh/year).

\subsubsection{Pacific OECD (PAO)}

In Pacific OECD countries, including e.g. Australia, New Zealand and Japan, the installed stock is expected to increase from 71 million (2010) to 86 million units in 2030. Most of the current washing machines are VA units, and especially impeller type machines are popular. Households in the region run more wash cycles per year than e. g. households in Europe, which correlates with the dominating VA technology and the use of frequent and short cold or lowtemperature washing programs [1].

Nevertheless, efficiency measures were implemented and sales numbers show that purchases are already gradually migrating from VA top loaders to more efficient HA front loaders. Therefore, general trends and improvement options are similar to NAM region. Stock model results for PAO show overall electricity saving potentials of $26.8 \%$ in 2030 , when comparing the absolute energy consumption of WM in the efficiency scenario (5.5 TWh/year) with the baseline scenario (7.5 TWh/year).

\subsubsection{Centrally planned Asia and China (CPA)}

For CPA, despite the fast increasing standard of living especially in China [13], electricity and water consumption for automatic laundry washing per household is still considered to be comparatively low. This is due to the lower number of about 100 wash cycles per year and the fact that a significant part of the residential washing is performed in cold water [1]. But even for people owning a washing machine, manual washing especially for delicates is still common. Hence, the overall electricity and water consumption for all laundry washing may be already higher than estimated for using washing machines only. However, the most relevant aspect is that the stock of installed automatic washing machines in the region is expected to increase significantly from 248 million (2010) to 462 million installed units in 2030, and hence also their environmental impacts.

The current market is divided between the traditionally dominating VA impeller type machines and HA washing machines [14]. Thereby, the low-income sector still focuses on inexpensive VA machines, whereas mid and high income sectors prefer advanced VA models with improved functions. HA washing machines market shares are also growing fast, although having entered this market relatively recently. This trend seems to be driven by consumers' desire for washing machines with larger washing capacities but smaller and stackable outer dimensions, as well as low abrasion of clothes, high rates of washing ability and sanitizing technologies [5]. 
Consequently improvement options refer both to VA and HA machines, correspondingly to NAM, WEU/EEU and PAO regions. However, especially the availability of inefficient old HA models with internal electric heating features and user behaviour have to be addressed to avoid an uncontrolled, altered washing behaviour from cold to more hot wash cycles per year. Taking these aspects into account, the performed stock model results for CPA show significant electricity saving potentials of $49.1 \%$ in 2030, when comparing the energy consumption in the efficiency scenario (34.5 TWh/year) with the baseline scenario (67.7 TWh/year).

\subsubsection{South Asia (SAS)}

For South Asia (SAS), India is a highly relevant potential leading market for washing machines [15]. So far, ownership rates for household appliances in India are still very low and only about $6 \%$ of the total population used a washing machine in 2010. Rural India, which accounts for about $70 \%$ of the total households, even had only a $0.5 \%$ ownership rate [16]. Many less affluent households still prefer to wash clothes manually rather than to invest in washing machines. Water scarcity in many Indian cities and frequent power blackouts are other major obstacles. However, it is expected that due to rising living standards and electrification the ownership rate of washing machines will increase significantly in the future [16]. Hence, the stock of installed machines is expected to rise from about 21 million (2010) to 151 million units in 2030.

The current market in India is thereby segmented into fully automatic machines and the still dominating and very low-priced semi-automatic machines [17], which had a market share of about $85 \%$ in the starting year (2010) of the scenarios [16]. Out of the automatic washing machine market, about one third of the machines were HA units. However, the composition of the stock and therefore, also the electricity consumption of washing machines in India is expected to change significantly, especially under consideration of a potential shift from mostly cold to more warm wash cycles [1]. Consequently improvement options refer both to VA and HA machines, correspondingly to CPA. Hence, also stock model results for SAS show significant electricity saving potentials of $38.9 \%$ in 2030 , when comparing the absolute energy consumption of WM in the efficiency scenario (8.3 TWh/year) with the baseline scenario (13.6 TWh/year).

\section{Conclusions}

Based on an extensive data gathering for washing machines, worldwide and regional saving potentials for washing machines have been assessed by means of a bottom-up stock modelling approach. The results reveal an expected worldwide stock increase of about $70 \%$ for washing machines be- tween 2010 and 2030. In combination with an expected change of washing habits, in the baseline scenario for this period (which already presumes a moderate efficiency improvement, based on the continuation of current trends), electricity consumption of washing machines would rise by more than $90 \%$ and the water consumption by more than $35 \%$.

In contrast, the performed impact assessment has shown that by using existing BAT and forthcoming BNAT technologies, it is alternatively also possible to halve the worldwide electricity demand for washing machines in 2030 compared to the baseline development. In the efficiency scenario significant savings compared to BAU are possible especially in developing and emerging regions such as CPA with China or SAS with India, where the stock is expected to rise massively between 2010 and 2030 .

However, a fast and comprehensive market transformation towards very energy efficient appliances is unlikely to happen itself [18], as indicated by many relevant reports, such as [19] or [20]. Therefore, further and more ambitious policy packages are needed worldwide [21], also to address other aspects [22], such as user behaviour [23]. Due to the large available GHG saving potentials, the topic is thereby also closely related to recent developments following the COP21 climate negotiations in Paris and the defined 'Intended Nationally Determined Contributions' (INDC). Globally for all countries much more efforts are needed to reach the agreed GHG saving and sustainability targets. Thus, it would be highly advisable for policy makers to use adequate policies [24] to foster significantly technological innovations and societal benefits by a broad diffusion of efficient appliances to realise the available saving potentials as demonstrated by this paper.

\section{References}

1. Pakula, C. and Stamminger, R.: Electricity and water consumption for laundry washing by washing machine worldwide, Energy Efficiency 3 (2010) 365 382. DOI: 10.1007/s 12053-009-9072-8

2. ACEEE (2011): American Council for an Energy-Efficient Economy, Washington, D.C, http://www.aceee.org/topics/laundry, Accessed: 09/2011.

3. Faberi, S., Presutto, M., Stamminger, R., Scialdoni, R., Mebane, W. and Esposito, R.: Preparatory Studies for Eco-design Requirements of EuPs (Tender REN/D 1/40-2005), LOT 14: Domestic Washing Machines and Dishwashers Final Report, Tasks $1-2$ (2007).

4. Save our Water: Save our Water Clothes Washer Rebate Program. Residential rebate program - fact sheet. http://www.energy.ca.gov/2015publications/ CEC-400-2015-017/CEC-400-2015-017-FS-REV.pdf (Accessed 03/2016) (2015).

5. IEA-4E: Efficient Electrical End-Use Equipment, Documents related to the mapping and benchmarking of Domestic Washing Machines (2011). http://mappingandbenchmarking.iea-4e.org (03/2016).

6. Josephy, B., Bush, E., Nipkow, J. and Attali, S: Washing Machines, Key Criteria for Best Available Technology (BAT), Topten International Services (Paris, France), (2011).http://www.topten.eu (Accessed 03/2016).

7. Götz, T. and Barthel, C.: Technical background and design options to raise energy efficiency and reduce the environmental impact of domestic washing machines, bigee.net worldwide Appliances Guide, Published 03/2013.

8. AATCC, American Association of Textile Chemists and Colorist: High Efficiency Washers in North America, (Accessed 09/2011)

http://www.aatcc.org/testing/resources/docs/204-HiEfWash.pdf 
9. ECN: Modelling the energy use of products: A review of approaches from practice (2011). http://www.ecn.nl/docs/library/report/2011/e11027.pdf, DEESY bottom-up accounting stock model.

10. CLASP/LBNL: CLASP Policy Analysis Modeling System (PAMS) (2007). http://www.clasponline.org/en/ResourcesTools/Tools/PolicyAnalysisModeling System.

11. World Energy Council (WEC): World Energy and Climate Policy: 2009 Assessment. Geneva, Switzerland.

12. US Residential Energy Consumption Survey, RECS: U.S. Energy Information Administration 2009, ElA, (Accessed 03/2016), http://www.eia.gov/consumption/residential/data/2009/

13. Biermayer, P. J. and Lin, J.: Clothes Washer Standards in China - the Problem of Water and Energy Trade-offs in Establishing Efficiency Standards, Lawrence Berkeley National Laboratory (LBNL), Conference Paper, 2004 ACEEE Summer Study, August 22 - August 27, 2004, 2004-05-19, LBNL-55115.

14. Fridley, D., Aden, N., Zhou, N. and Lin, J.: Impacts of China's Current Appliance Standards and Labeling Program to 2020, Lawrence Berkeley National Laboratory Environmental Energy Technologies Division March 2007 DOI: $10.2172 / 920173$

15. GfK Retail and Technology Asia: Washing Machine Sales Spur Growth of the Major Domestic Appliances Sector in Southeast Asia: GfK Asia, July 21, 2011 Singapore.

16. Productivity in: Productivity \& Competitiveness of Light Electrical Industry in India - Report 1, Main Report, Department of Industrial Policy \& Promotion (DIPP), Ministry of Commerce and Industry, Government of India, study submitted by the National Productivity Council, Economic Services Group (2009)

17. World Bank: Residential consumption of electricity in India, documentation of data and methodology, Background Paper India: Strategies for Low Carbon Growth, July 2008, The World Bank, http://moef.nic.in/downloads/ public-information/Residentialpowerconsumption.pdf.

18. Thomas, S.: Aktivitäten der Energiewirtschaft zur Förderung der Energieeffizienz auf der Nachfrageseite in liberalisierten Strom- und Gasmärkten europäischer Staaten: Kriteriengestützter Vergleich der politischen Rahmenbedingungen. Wuppertal 2007.

19. Sorrell, S., O'Malley, E., Schleich, J. and Scott, S.: The Economics of Energy Efficiency, Barriers to Cost-Effective Investment. Cheltenham. Edward Elgar Publishing Limited 2004. DOI: 10.1002/eet.383

20. Zhou, N., Zheng, N. and Fridley, D.: International Review of the Development and Implementation of Energy Efficiency Standards and Labeling Programs (2012). DOI:110.2172/1082202

21. Tholen, L. and Thomas, S.: Combining theoretical and empirical evidence: Policy packages to make energy efficiency in appliances happen. In: EEDAL 11 Energy Efficiency in Domestic Appliances and Lighting - 2011

22. Bundgaard, A., Overgaard Zacho, K. and Remmen, A.: Product policies on the environmental performance of washing machines. Investigating the synergies and coherence between policy instruments (2013). DOl:10.6027/tn2013-549

23. Berkholz, P., Stamminger, R., Kruschwitz, A. and Brückner, A.: Definition und Ermittlung verhaltensabhängiger Energiesparpotentiale beim Betrieb elektrischer Haushaltswaschmaschinen, Bonn 2006.

24. Thomas, S., Aydin, V., Kiyar, D., Tholen, L. and Venjakob, M.: Strategic policy packages to deliver energy efficiency in buildings - their international evidence. In: eceee Summer Study 2013.

Received: 04. 04. 2016

Revised: 13. 07. 2016

\section{Bibliography}

DOI 10.3139/113.110460

Tenside Surf. Det.

53 (2016) 5; page 410-416

(c) Carl Hanser Verlag $\mathrm{GmbH} \& \mathrm{Co} . \mathrm{KG}$

ISSN 0932-3414

\section{Correspondence address}

\section{Mr. Thomas Götz}

Research Group "Energy, Transport and Climate Policy"

Wuppertal Institute for Climate, Environment and Energy

Döppersberg 19

D-42103 Wuppertal

Germany

Tel.: +49(0)2022492-213

E-Mail: thomas.goetz@wupperinst.org

\section{The authors of this paper}

Thomas Götz is working as research fellow in the Research Group "Energy, Transport and Climate Policy" at the Wuppertal Institute for Climate, Environment and Energy. He studied Geoecology at Karlsruhe Institute of Technology (KIT), Germany with focus on environmental economics, industrial ecology as well as energy- and material flows. He worked at the Fraunhofer Institute for Systems and Innovation Research, ISI, Competence Centre Sustainability and Infrastructure Systems and joined the Wuppertal Institute in 2009 . His focus of work is research and coordination of national, European and international projects in the fields of energy- and resource efficiency in buildings (appliances, heating systems), (EU) Ecodesign and Energy Labelling as well as emission reduction measures and impact assessments.

Lena Tholen studied Environmental Sciences at the Leuphana University of Lüneburg, Germany with a focus on energy policy, environmental law and sustainability communication. She joined the Wuppertal Institute for Climate Environment and Energy in 2008 and works as a Research Fellow in the Research Group "Energy, Transport and Climate Policy". Lena Tholen is involved in several national, European and international research projects on energy and resource efficiency with a main focus on policies and measures, impact evaluation as well as aspects of EU Ecodesign and Energy Labelling. 